\title{
The Solution to China's Current Excessive Interior Design
}

\author{
Zhongcui Zhu \\ Shanghai Publishing and Printing College, Shanghai, 200093, China \\ Laiyangli01@163.com
}

Keywords: Excessive design; Interior design; Green design; Sustainable development

\begin{abstract}
With the development of society and the prosperity of science and technology, crazy exploiting by human beings, paying no attention to the complementarity and protection of resources, these result in strict overall consequences. Only the green design with the establishment of "sustainable development" mode of production is the right direction of contemporary Chinese interior design.
\end{abstract}

\section{Stop Misuse of Resources, Promote Green Design}

Green design is a product design that achieves green product design requirements. Green design is based on the concept of environmental resources as the core of the design process, that is, within the product's entire life cycle, giving priority to product environmental attributes (removable, recyclable, etc.), and considering those as product design target, to meet environmental goals while ensuring physical target product (basic performance, service life, quality, etc.). Therefore, a comprehensive green design is a development of object-oriented technology, concurrent engineering, life cycle design in the design, comprising a recycled product from concept to manufacturing, as well as waste after use, reuse and treatment the various stages that involves the entire product life cycle, from the "Cradle to the Reproduction" process.

Resources, environment and population are the three major problems facing humanity today. The establishment of "sustainable development" mode of production has been taken as a development strategy by more and more countries.

"GREEN THEORY "economy appeared with the use of advanced technology and the green products. Green cars, green refrigerator, green packaging and other environmentally friendly products continue to emerge. Those are setting off a green wave. However, the construction industry, as a pillar industry to create human wealth, consumed a lot of the limited resources of human society and is one of the major root causes of the current problems of environmental pollution. Therefore, green design is the inevitable trend of the development of the construction industry.

\section{The Building is Over-design Resulted in Pressure on The Environment}

There are more damage to the environment and waste of resources in many interior designs of buildings. To sum up, the following aspects should be considered: irrational function design, excessive design, structural re-construction, excessive building energy waste and inappropriate usage of materials.

Irrational Function Design. All kinds of waste caused by irrational function design are often latent in design. The lack of ability to grasp the function of an organization and the lack of professional well trained from the interior designer is concerned. Interior partition appears in various ways contrary to the principle. That is disadvantages in solving the functional problem.

Excessive Design. It brings a great deal of waste that no considering functionality and performance characteristics of the room, no taking the interior design vocabulary and methods that best meet their own characteristics to complete and regardless of settings and location blindly stacking on design. Designers should take on the role of mentor to establish the correct values, carry out the spirit of compliance with environmental standards of beauty and persuade society to convince builders to produce values. 
Construction of the Building Structure Again. The interior decoration is always accompanied by a series of structural changes for whatever reason. These changes in the structure of the building itself not only affect the stability of the original structure but also cause a huge waste. A huge amount of waste removal and dust pollution have brought great harm to the environment. In the interior design stage, designers should take full account of the usage of existing structures and minimize the spatial structure of the second construction.

Excessive Waste of Energy. Energy savings from the most fundamental is to save resources. In the design designers should take full account of how to maximize energy savings. The largest indoor environmental control energy consumption often comes from the equipment requirements. The way of saving energy should be avoiding use a lot of excessive or unnecessary equipment. The natural energy should be gradually introduced into the interior design such as wind, solar and geothermal use.

Improper Use of Building Materials. Interior decoration is made of various types of building materials and construction organization. Rational use of building materials has become the key to interior design. Building materials it is the core of "green" issues.

\section{Interior Design Development - towards Green Design}

The overall design principles of "green" energy are the energy optimization principle and the production of waste minimization principles. These principles embody the following areas:

Promoting Moderate Consumption. The important content in the consumer inhabitable is to create an artificial environment by interior decoration. Unlike in the past, the interior design advocate moderate consumption of ecological thinking, promote saving way of life and maintain the production and consumption within the carrying capacity of resources and the environment, maintain sustainable development. That reflects a new Ecological and cultural values.

Paying Attention to Ecological Aesthetics. Ecological aesthetics is the development of a new aesthetic and a harmonious organic beauty which added the traditional aesthetic to the ecological factors. It emphasizes the natural ecological beauty, appreciate the rustic, simple and not deliberately carving in the indoor environment decoration; It also emphasized creating artificial ecological beauty, the integration of interior landscape and nature under the premise human ecological laws and Laws of beauty with using the scientific and technological means. It brings not only the visual shock people but lasting spiritual pleasure.

The use of Natural Light and Natural Ventilation. "Green" transformation of spatial structure can be appropriately improved natural light and ventilation, but it's not enough. The introduction of natural light not only creating an atmosphere of space but also enhancing the natural sense of interior space to meet the indoor lighting. We can also use some better materials make better light such as glass, mirrors or some organic light-transmitting plastic and other materials and do reflection and refraction designs to further use natural light. Meanwhile, natural ventilation is a relatively mature technology and inexpensive measures widely used in today's eco-design.

The use of "Green Materials". The use of "green materials" is one of the essential elements in interior design and also currently a topic of great concern to the people. The concept of green materials first proposed in the international scientific conference material in1988. In 1992 the international academic community defined the green material as: taking raw materials, product manufacturing, application process and subsequent use and recycling and other aspects of the minimum load on human health and harmful material on the global environment.

To Create a "Green" Renovation Process. Decoration itself is part of the work of the designer. A good designer should know how their work will undergo a renovation process. Therefore, the designer should take all sorts of problems into consideration, such as how to plan a simple renovation process; how to save timber, saving energy and how to reduce noise pollution.

Promote Conservation and Recycling. Eco interior design emphasizes that we should save and recycle the average energy and non-renewable resources, also try to lower consumption use of renewable resources.in the process of interior construction, usage and renovation. Expanded ecological thought into the interior design and extended the connotation of interior design that not 
only brings interior design to a higher level and state, but also promotes the usage of the earth's resources in construction turn from consumption to recycling.

\section{Conclusion}

To sum up, we can draw the following conclusions:

Interior design is no longer the designer's work; it requires the coordination and cooperation of all relevant professional designers and engineers. We can say that a successful eco-design must be the result of the whole team cooperation.

To realize ecological design is the trend of these times is imperative in architecture and interior design industry. The designers should bear the historical responsibility nowadays.

The Earth is the only one human live. As an interior designer, we should know that only through green design can we achieve sustainable development of the construction of the indoor environment. Only in this way, can we make our home harmony!

\section{References}

[1] Qiman Zhang: The Style Model and School of Interior Design, [M], Beijing: China Architecture \& Building Press, 2000, in Chinese.

[2] Pingxi Xiao: Submitted to Journal of Chongqing University (Social and Science Edition), 2005(4), p17-21, in Chinese.

[3] Xinsheng Chen, Bei Chen: Decorativation, 2006(2), p108, in Chinese.

[4] Liangyong Wu: The General Theory of Architecture, [M], Beijing: Tsinghua University Press, 2011, in Chinese.

[5] Suping Jiao, Qi Zhang: Contemporary Foreign Architecture and Interior Design, [M], Beijing: China Architecture \& Building Press, 2005, in Chinese.

[6] Zhongcui Zhu: The principle and application of green interior design, urban construction theory research. 2012, in Chinese.

[7] Qingqing $\mathrm{Xu}$ : Based on the evaluation system of green interior design research [D], Donghua University, 2014, in Chinese.

[8] Lee, A. Allen, B. Kim: Interior design practitioner motivations for specifying sustainable materials: applying the theory of planned behavior to residential design, J. Inter. Des., 38, 2013.

[9] Zhongcui Zhu: The Appearance and Support of Mind-Style Preference and Social Background of the Contemporary Interior Design, Advanced Materials Research, 2012.

[10] John Wiley \& Sons Inc.: Environmentally Responsible Design: Green and Sustainable Design for Interior Designers, New Jersey, 2008, Edited by L. Jones. 